\title{
The effect of Channa striata extract and standard eradication regimen on asymmetric dimethylarginine in Helicobacter pylori gastritis rat model
}

\author{
OK Yulizal ${ }^{1,2}$, Aznan Lelo3 ${ }^{(D)}$, Syafruddin Ilyas $^{4}(\mathbb{D})$ and Raden Lia Kusumawati5
}

1. Department of Internal Medicine, Faculty of Medicine, Universitas Prima Indonesia, Medan, Indonesia; 2. School of Medicine, Universitas Sumatera Utara, Medan, Indonesia; 3. Department of Pharmacology and Therapeutics, School of Medicine, Universitas Sumatera Utara, Medan, Indonesia; 4. Department of Biology, Faculty of Mathematics and Natural Sciences, Universitas Sumatera Utara, Medan, Indonesia; 5. Department of Microbiology, School of Medicine, Universitas Sumatera Utara, H. Adam Malik General Hospital, Medan, Indonesia.

Corresponding author: OK Yulizal, e-mail: yulizal.tech@gmail.com

Co-authors: AL: aznanlelo@yahoo.com, SI: syafruddin6@usu.ac.id, RLK: liaiswara@yahoo.com

Received: 06-03-2020, Accepted: 24-06-2020, Published online: 17-08-2020

doi: www.doi.org/10.14202/vetworld.2020.1605-1612 How to cite this article: Yulizal OK, Lelo A, Ilyas S, Kusumawati RL (2020) The effect of Channa striata extract and standard eradication regimen on asymmetric dimethylarginine in Helicobacter pylori gastritis rat model, Veterinary World, 13(8): 1605-1612.

\begin{abstract}
Background and Aim: The presence of gastric mucosa or submucosa inflammation due to Helicobacter pylori leads to histological changes. Gastric injury, pro-inflammatory factors, and oxidative stress in H. pylori infection produce asymmetric dimethylarginine (ADMA), which are a competitive inhibitor of nitric oxide synthase. Investigations were carried out aimed at finding new drugs derived from natural products for the treatment of $H$. pylori. Channa striata is known to have in vitro anti-inflammatory and antimicrobial properties. This study aimed to investigate the effect of $C$. striata extract and a standard eradication regimen on ADMA levels and histological changes in the H. pylori gastritis rat model.
\end{abstract}

Materials and Methods: Thirty-five male rats were randomly and equally divided into five groups. Group- 1 was the negative control group and Groups-2 to 5 were $H$. pylori-infected groups. Groups-3 to 5 were administered $C$. striata extract, a standard eradication regimen, and a combination of standard eradication regimen and C. striata extract, respectively. Histological examination and serum ADMA levels were analyzed. The difference between groups was analyzed using the Kruskal-Wallis and one-way analysis of variance tests. The significance was $\mathrm{p}<0.05$.

Results: Serum ADMA levels and severity of gastritis were higher in infected groups compared to the negative control group $(\mathrm{p}<0.05)$. The severity of gastritis and mean ADMA levels in the group that received a single administration of the C. striata extract was higher than the others $(\mathrm{p}<0.05)$. Serum ADMA levels and severity of gastritis were significantly reduced in the group that received a combination of standard eradication regimen and $C$. striata extract $(\mathrm{p}<0.05)$.

Conclusion: Single administration of $C$. striata extract worsens the severity of gastritis and increased serum ADMA levels in the $H$. pylori gastritis rat model. The administration of a combination of standard eradication regimen and $C$. striata extract reduces serum ADMA levels and significantly improves the severity of $H$. pylori gastritis rat model.

Keywords: asymmetric dimethylarginine, Channa striata, eradication regimen, Helicobacter pylori gastritis, histological changes.

\section{Introduction}

Helicobacter pylori is a bacterium that causes damage to the gastric mucosa, commonly in the form of gastritis, peptic ulcer disease, or even gastric malignancy [1]. Gastritis is the most common clinical manifestation of $H$. pylori infection. The occurrence of gastric mucosa or submucosa inflammation due to $H$. pylori causes mild-to-severe histological changes. The degree of gastritis is related to the density of $H$. pylori, gastric mucosal injury, and inflammation [2]. Gastric mucosal injury is characterized by an increase in endogenous nitric oxide synthase (NOS)

Copyright: Yulizal, et al. Open Access. This article is distributed under the terms of the Creative Commons Attribution 4.0 International License (http://creativecommons.org/licenses/by/4.0/), which permits unrestricted use, distribution, and reproduction in any medium, provided you give appropriate credit to the original author(s) and the source, provide a link to the Creative Commons license, and indicate if changes were made. The Creative Commons Public Domain Dedication waiver (http://creativecommons.org/ publicdomain/zero/1.0/) applies to the data made available in this article, unless otherwise stated. inhibitor levels, namely, asymmetric dimethylarginine (ADMA) [3]. An increase in ADMA levels leads to the reduction of nitric oxide (NO) through the inhibition of NOS activity, and an enzyme generates NO from arginine [4]. NO plays a role in preserving the gastric mucosa through the maintenance of mucosal perfusion, and some studies have noted that ADMA could be a marker for gastric mucosal injury. ADMA is a substance that plays a role in the process of atherogenesis and is closely associated with diseases linked to that process [5]. Inflammation is characterized by changes in cytokines, especially pro-inflammatory cytokines. Changes in these cytokines will ultimately bring about increased ADMA production [6].

Management of $H$. pylori infections has progressed since this bacterium was popularized by Barry Marshall and Robin Warren several decades ago. The discovery of several $\mathrm{H}$. pylori eradication treatment regimens continues to be the aim of finding new drugs 
as well as increasing the effectiveness of existing eradication regimens. There are several known reasons for the reduced efficacy of the H. pylori standard eradication regimen, including patient compliance, immunity status, nutrition, and antimicrobial resistance [7]. The reduced effectiveness of the $H$. pylori standard eradication regimen causes antimicrobial resistance, a severe problem mainly in areas with high levels of antimicrobial resistance [8]. In an effort to eradicate $H$. pylori and to reduce the level of antimicrobial resistance, investigations are currently being conducted to find new drugs that come from natural sources, including plant and animal extracts, for use as a single drug or in combination with current eradication regimens. The selection of alternative and additional drugs for the treatment of $H$. pylori infection is also aimed at reducing the side effects of certain medications, lowering treatment costs, and assessing the antimicrobial and anti-inflammatory properties of the extracts [7]. Channa striata is a species of predatory fish that lives in the Asia Pacific region and is widely consumed by its inhabitants [9]. C. striata extract is a source of animal protein and is believed to contain nutrients that are important in improving body stamina after labor, surgery, and healing after suffering from certain diseases. Researchers have characterized the high nutrient content of this fish, including the protein, albumin, amino acid, fatty acid, vitamin, and mineral content. All of these nutrients are very useful in the prevention and treatment of several diseases [10]. C. striata extract reportedly has anti-inflammatory, antioxidant, and anti-gastric ulcer properties $[9,11]$. Several studies have documented the potential role of $C$. striata extract in vitro as an antimicrobial and antifungal $[12,13]$.

Based on the in vitro antimicrobial properties and in vivo anti-inflammatory properties of $C$. striata extract, we are interested in testing its potential for reducing injury to the gastric mucosa by assessing the ADMA levels and the histological features in the H. pylori gastritis rat model. This study aimed to investigate ADMA levels and histological changes after administration of $C$. striata extract as a single drug and or in combination with the $H$. pylori standard eradication regimen in the $H$. pylori gastritis rat model.

\section{Materials and Methods}

Ethical approval

All experiments and procedures of this research were conducted after gaining approval from the Animal Research Ethics Committee, Department of Biology, Faculty of Mathematics, and Natural Sciences, Universitas Sumatera Utara, Medan, Indonesia, with approval number 0448/KEPH-FMIPA/2019.

\section{Study period and location}

This study was performed from October to December 2019 at Microbiology Laboratory, Biomedical Research Unit, West Nusa Tenggara Province General Hospital, Indonesia.

\section{Study design}

This experimental study used a post-test only with the control group design and determination of samples by simple random sampling.

\section{Experimental animals}

This study involved 35 male albino rats of the species Rattus norvegicus Wistar strain purchased from Biomedical Research Unit, West Nusa Tenggara Province General Hospital. The rats were 8-12 weeks old, with mean body weight (BW) of $294 \mathrm{~g}$, and showing active movement and good appetite. They were housed in cages subjected to a $12 \mathrm{~h}$ light/dark cycle, at room temperature $27 \pm 2^{\circ} \mathrm{C}$ with $70-80 \%$ humidity. The cages were sanitized regularly, fed with standard commercial rodent food, and provided with water ad libitum. The rats were acclimated for 7 days in the laboratory, then divided randomly into five groups of seven each, namely: (1) Group-1 (negative control, without $H$. pylori inoculation); (2) Group-2 (positive control, H. pylori infection rat model); (3) Group-3 (H. pylori infection rat model $+C$. striata extract with a dose of $300 \mathrm{mg} / \mathrm{kg} \mathrm{BW}$ ); (4) Group-4 (H. pylori infection rat model + standard eradication regimen (aqueous solution of amoxicillin $50 \mathrm{mg} / \mathrm{kg} \mathrm{BW}+$ clarithromycin $25 \mathrm{mg} / \mathrm{kg} \mathrm{BW}+$ omeprazole $20 \mathrm{mg} / \mathrm{kg}$ $\mathrm{BW}$ ); and (5) Group-5 (H. pylori infection rat model + a combination of standard eradication regimen (aqueous solution of amoxicillin $50 \mathrm{mg} / \mathrm{kg} \mathrm{BW}+$ clarithromycin $25 \mathrm{mg} / \mathrm{kg} \mathrm{BW}+$ omeprazole $20 \mathrm{mg} / \mathrm{kg} \mathrm{BW}$ ) and C. striata extract with a dose of $300 \mathrm{mg} / \mathrm{kg} \mathrm{BW}$.

\section{H. pylori preparation}

The H. pylori isolate was obtained from the gastric biopsy specimen of a duodenal ulcer patient, which was kept and cultured at the Microbiology Laboratory, Biomedical Research Unit, West Nusa Tenggara Province General Hospital. H. pylori from this human isolate was cultured using Tryptic Soy Agar to which $10 \%$ fresh sheep blood, $2 \mathrm{~mL} / 500 \mathrm{~mL}$ Dent supplement, and $10 \mathrm{~mL} / 500 \mathrm{~mL}$ Vitox supplement (Oxoid ${ }^{\mathrm{TM}}$, Thermo Scientific ${ }^{\mathrm{TM}}$, Hampshire, UK) were added. Incubation was carried out in a $\mathrm{CO}_{2}$ incubator under microaerophilic atmospheric conditions with a concentration of $5 \% \mathrm{O}_{2}, 10 \% \mathrm{CO}_{2}$, and $85 \% \mathrm{~N}_{2}$ for $72 \mathrm{~h}$ at $37^{\circ} \mathrm{C}$. Then, the colonies suspected of being $H$. pylori were confirmed by appearance, microscopic Gramstaining, and biochemical analysis (oxidase, catalase, and urease). The rats in Groups 2, 3, 4, and 5 were inoculated with $H$. pylori suspension containing $5 \times$ $10^{8}-5 \times 10^{10}$ colony-forming units $/ \mathrm{mL}$ equivalent to 2.0 McFarland standard in $0.9 \% \mathrm{NaCl}$ at $1 \mathrm{~mL} /$ rat.

\section{C. striata extract and standard eradication regimen}

The $C$. striata extract was obtained from Channa ${ }^{\circledR}$ capsules (PJ. Herbal Nusantara, Solo, Indonesia) and purchased from a retail drug store. Each $500 \mathrm{mg}$ capsule contained pure $C$. striata extract powder. The biochemical compounds of Channa ${ }^{\circledR}$ capsules were analyzed at the Department of Pharmacy, Universitas Muhammadiyah Surakarta, Middle Java, Indonesia. 
C. striata extract was dissolved in $0.5 \%(\mathrm{w} / \mathrm{v})$ carboxymethyl cellulose $(0.5 \% \mathrm{CMC})$ and administered orally by intragastric tube at $1 \mathrm{~mL} /$ rat once a day. A dose of $300 \mathrm{mg} / \mathrm{kg} \mathrm{BW}$ was used as a treatment dose, which was converted from a human dose, as reported by an earlier study [14]. The standard eradication regimen consisted of amoxicillin, clarithromycin, and omeprazole (PT. Indofarma, Jakarta, Indonesia) in aqueous solution (dissolved in $0.5 \% \mathrm{CMC}$ ) at a dose of $50 \mathrm{mg} / \mathrm{kg} \mathrm{BW}, 25 \mathrm{mg} / \mathrm{kg} \mathrm{BW}$, and $20 \mathrm{mg} / \mathrm{kg} \mathrm{BW}$, respectively, all purchased from a commercial drug store.

\section{Experimental procedure}

After 7 days of the acclimation period, rats in Group-1 were given ordinary drinking water, while Groups-2 to -5 were pre-treated with streptomycin (PT. Indofarma, Jakarta, Indonesia) suspended in tap water $(5 \mathrm{mg} / \mathrm{mL})$ for $72 \mathrm{~h}$ prior inoculation of H. pylori. The streptomycin was purchased from a retail drug store. All rats then fasted for $24 \mathrm{~h}$ the next day, and Group-1 was supplemented with a solution of $0.9 \%(\mathrm{w} / \mathrm{v})$ sodium chloride $(0.9 \% \mathrm{NaCl})$ at $1 \mathrm{~mL} / \mathrm{rat}$ orally by intragastric tube twice a day at an interval of $4 \mathrm{~h}$ for 3 consecutive days. In addition, Groups- 2 to -5 were inoculated with an aqueous $1 \mathrm{~mL} /$ rat suspension of $H$. pylori orally by intragastric tube twice a day at an interval of $4 \mathrm{~h}$ for 3 consecutive days. Three hours before the first of $H$. pylori inoculation and during the following 6 days, the rats in Groups-2, 3, 4, and 5 were administered omeprazole (PT. Indofarma, Jakarta, Indonesia) orally, at a dose of $400 \mu \mathrm{mol} / \mathrm{kg} \mathrm{BW}$ dissolved in $0.5 \% \mathrm{CMC}$, purchased from a commercial drug store, and $1 \mathrm{~mL} /$ rat once a day orally by intragastric tube, whereas the rats in Group-1 were given a $0.5 \%$ CMC suspension following the same procedure.

Two weeks after the last day of $H$. pylori inoculation, all rats fasted overnight before treatment. A rat from each group was randomly selected and sacrificed under diethyl ether anesthesia in a chamber for the monitoring $H$. pylori infection. A rat selected from each group was carried out to a midline laparotomy device. The stomach was removed, gastric mucosa from the antral area $\left(2 \mathrm{~mm}^{2}\right)$ was cut out, and a urease test (Pronto Dry ${ }^{\circledR}$, Gastrex, France) was performed for the detection of $H$. pylori in gastric tissue. This procedure produced a positive urease test in all rats that represented the inoculation groups.

The next day, the remaining rats from each group were treated accordingly. The rats in Groups- 1 and -2 were administered $0.5 \% \mathrm{CMC}$ suspension orally once daily by intragastric tube for 7 days. Meanwhile, the rats in Group-3 received the C. striata extract orally $1 \mathrm{~mL} /$ rat once daily through an intragastric tube for 7 days. The rats in Group- 4 were administered the standard eradication regimen orally at $1 \mathrm{~mL} /$ rat for 7 days, and the rats in Group-5 were administered the standard eradication regimen and $1 \mathrm{~mL} / \mathrm{rat}$ C. striata extract at an interval of $6 \mathrm{~h}$ orally, respectively, once daily by intragastric tube for 7 days. All rats were sacrificed under diethyl ether anesthesia in a chamber, 4 weeks after this treatment protocol. The laparotomy procedure was followed to perform a rapid urease test, as in the previous description. All animals were successfully infected with $H$. pylori in the infected groups. Furthermore, gastric antral was provided for histological examination, and the blood was taken directly from the heart.

\section{Histological and ADMA examination}

Gastric mucosal tissue in a small fragment from the antral region was removed and fixed with $10 \%$ buffered neutral ( $\mathrm{pH}$ 7.4) formalin solution for $24 \mathrm{~h}$, and tissue processing and embedding were then carried out on the paraffin block. The paraffin block was cut to a thickness of $5 \mu \mathrm{m}$ and placed on slides before staining. The procedure was continued using the hematoxylin-eosin staining technique. Microscopic examination was conducted blindly by a pathologist. The severity of gastritis and bacterial colonization was scored and classified using the updated Sydney system (USS) to assess lymphocyte infiltration, neutrophil activity, glands atrophy, intestinal metaplasia, and density of $H$. pylori [15].

The blood from each rat was collected through a cardiac puncture and allowed to clot for $2 \mathrm{~h}$ at room temperature. The clotted blood was then centrifuged at 3000 revolutions/min (rpm) for $20 \mathrm{~min}$ to obtain serum on the ADMA examination. The serum was removed and frozen at $-70^{\circ} \mathrm{C}$ until the day of analysis. The enzyme-linked immunosorbent assay kit (Cat. No. E0137Ra, Bioassay Technology Laboratory, Shanghai, China) was used to measure the ADMA levels accordingly.

\section{Statistical analysis}

The Shapiro-Wilk test was used to evaluate the normality of the quantitative variables. The results were presented as mean \pm standard deviation for normally distributed data and median (minimum-maximum) for non-normally distributed data. We computed the differences between the mean of quantitative variables with normal distribution using one-way analysis of variance (ANOVA) with post hoc Tamhane test and Kruskal-Wallis test for non-normal data distribution to compare and analyze data. The statistical software SPSS version 22.0 (IBM, Chicago, IL, USA) was utilized to perform computation, and $\mathrm{p}<0.05$ was determined as the significance of the limit.

\section{Results}

The severity of gastritis was assessed in this study through histological examination based on the USS. A tabulation of histological examination results is presented in Table-1. It shows more neutrophil cells in Groups-2 and -3 compared to the other groups (Kruskal-Wallis test, $\mathrm{p}<0.05$ ). In contrast, intestinal metaplasia and $H$. pylori density were more common in Group-3 than in other groups (Kruskal-Wallis test, 
$\mathrm{p}<0.05$ ). Histologically, the severity of gastritis was higher in Group-3, followed by Groups-2, $-4,-5$, and -1 , respectively (Kruskal-Wallis test, $\mathrm{p}<0.05$ ). Based on the results of the histological examination in rats of all groups, we found as many as $7 \%$ normal ones, $50 \%$ with mild gastritis, and $43 \%$ with moderate gastritis. No rat was classified as severe gastritis. In Figure-1, we present the microscopic images of gastric antral tissue in the histological examination.

Figure-2 shows the ADMA levels of each group. It was demonstrated that the mean ADMA levels in Group-3 were the highest compared to the other groups. The details of the difference are displayed in Table-2. A statistical test using one-way ANOVA showed a difference in the mean of ADMA levels between groups $(p<0.001)$. It demonstrated that the mean of ADMA levels in Group-3 was the highest, while the mean of ADMA levels in Group-1 was the lowest compared to the other groups. To determine the differences in the mean of ADMA levels between groups, a post hoc Tamhane analysis was carried out. The results of the analysis are displayed in Table-3.

\section{Discussion}

The technique of inducing H. pylori infection in rats' stomachs in this current study was in line with the previous research. The principle in the induction of $H$. pylori infection was to create an environment that supports the growth and colonization of $H$. pylori in the stomach, starting with pre-treatment of streptomycin and omeprazole to inhibit the growth of other bacteria and reduce the level of gastric acidity, respectively [16]. In this study, it can be proven that all rats in $H$. pylori inoculated groups showed positive urease test results.

We noticed some factors attributed to $H$. pylori infection, including high gastric acidity, gastric motility disorder, low albumin level, and biofilm formation [17-20]. High gastric acidity and gastric motility disorder occur due to an increase and disproportion of gastrin and somatostatin activity, respectively $[17,18]$. Low albumin levels as the result of decreased albumin synthesis, increased albumin degradation, and high transcapillary escape rate in the inflammatory condition [19]. Biofilms are layers of bacterial cells firmly attached to the surface, and can not be easily separated or moved. They are embedded in the self-generated

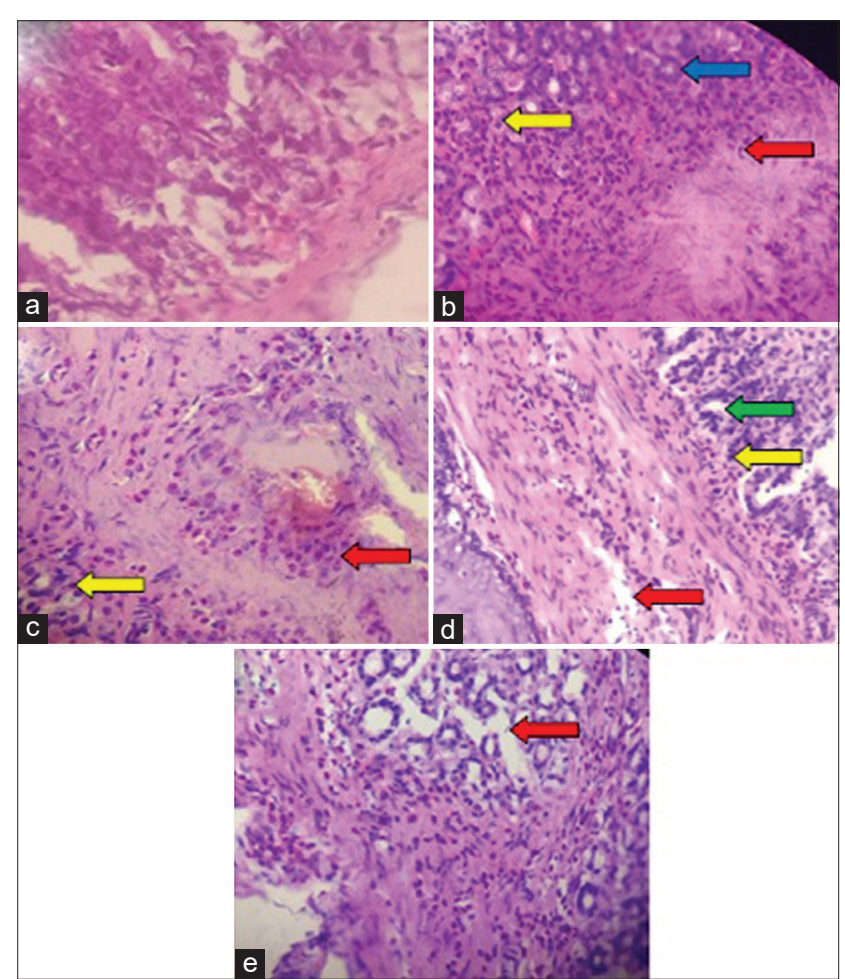

Figure-1: Histological representation of rat's gastric tissue (Hematoxylin and Eosin staining). (a) Group-1; (b) Group-2; (c) Group-3; (d) Group-4; (e) Group-5. Red arrows indicated Helicobacter pylori; yellow arrows indicated polymorphonuclear leukocytes cells; blue arrows indicated edema; green arrows indicated vasodilation. (Olympus ${ }^{\circledR}$ CX22 LED microscope with a magnification of $400 \times$ and photomicrographs were carried out with a Vivo ${ }^{\circledR} 9$ camera).

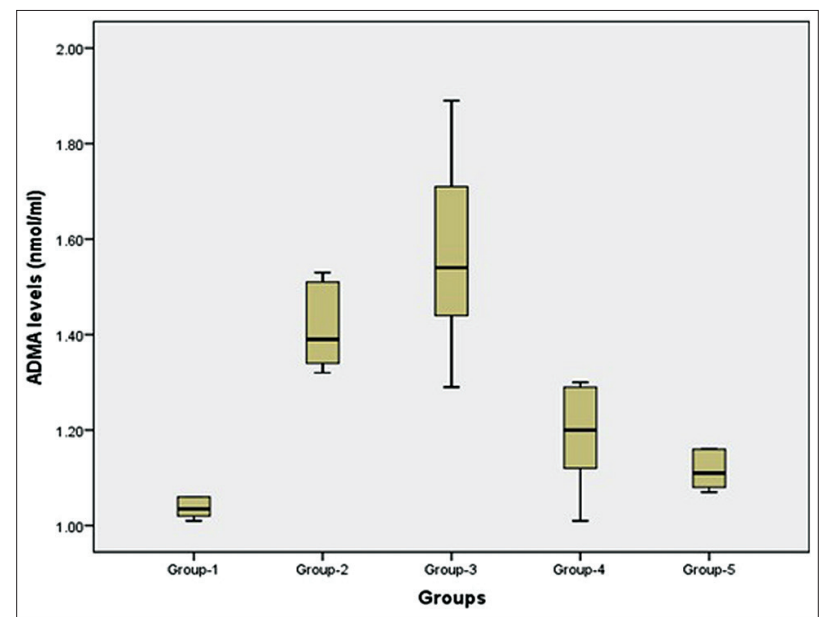

Figure-2: Boxplot asymmetric dimethylarginine levels of the experimental groups.

Table-1: Tabulation of histological examination results based on the USS.

\begin{tabular}{|c|c|c|c|c|c|c|c|}
\hline \multirow[t]{2}{*}{ Groups } & \multicolumn{5}{|c|}{ Variable } & \multirow{2}{*}{$\begin{array}{l}\text { USS total } \\
\text { score }\end{array}$} & \multirow[t]{2}{*}{ p-value } \\
\hline & Lymphocyte & Neutrophil & $\begin{array}{l}\text { Glands } \\
\text { atrophy }\end{array}$ & $\begin{array}{c}\text { Intestinal } \\
\text { metaplasia }\end{array}$ & $\begin{array}{l}\text { H. pylori } \\
\text { density }\end{array}$ & & \\
\hline Group-1 & $0.17 \pm 0.41$ & $1.00 \pm 0.89$ & $0.00 \pm 0.00$ & $0.00 \pm 0.00$ & $0.00 \pm 0.00$ & $1.17 \pm 1.17$ & $<0.001^{*}$ \\
\hline Group-2 & $1.17 \pm 0.41$ & $2.17 \pm 0.41$ & $0.83 \pm 0.41$ & $0.00 \pm 0.00$ & $1.33 \pm 0.52$ & $6.50 \pm 0.55$ & \\
\hline Group-3 & $1.17 \pm 0.41$ & $2.33 \pm 0.52$ & $1.17 \pm 0.41$ & $0.83 \pm 0.41$ & $2.33 \pm 0.52$ & $7.83 \pm 1.47$ & \\
\hline Group-4 & $1.17 \pm 0.41$ & $1.67 \pm 0.82$ & $0.50 \pm 0.55$ & $0.50 \pm 0.55$ & $1.33 \pm 0.52$ & $5.17 \pm 0.75$ & \\
\hline Group-5 & $0.67 \pm 0.52$ & $1.33 \pm 0.52$ & $0.67 \pm 0.52$ & $0.00 \pm 0.00$ & $1.00 \pm 0.63$ & $3.67 \pm 1.03$ & \\
\hline
\end{tabular}

Data expressed as mean \pm SD. Statistical test using one-way ANOVA. $* p<0.05$. USS=Updated Sydney System, $\mathrm{SD}=$ Standard deviation, ANOVA=Analysis of variance, $H$. pylori=Helicobacter pylori 
extracellular polymeric substances, including polysaccharides, nucleic acids, and proteins as their protectors. Nutritional sources of $H$. pylori biofilm derived from protein and fat metabolism [20]. Bacterial biofilms in the gastric mucosal epithelium, as in vivo, differ structurally and functionally from free-living/ planktonic bacteria (in vitro). When attached to the gastric mucosal epithelium, bacteria in a biofilm will obtain a regular supply of nutrients from the environment and host so that growth and colonization will be better maintained. The formation of bacterial biofilm leads to resistance to antimicrobial agents [21]. These factors contribute to the performance of agents or drugs in the eradication of $H$. pylori. Hence, the results of in vitro studies are often different from the results of in vivo studies.

Histological examination is a standard procedure to determine the severity of gastritis objectively based on the USS to assess lymphocyte infiltration, neutrophil activity, glandular atrophy, intestinal metaplasia, and H. pylori density. Gastritis is an inflammation of the gastric mucosa in response to gastric injury or infection. Gastritis caused by H. pylori is characterized by an increased density of mononuclear cells and polymorphonuclear activation, which generally associated with the density of $H$. pylori bacteria. H. pyloris high density will be directly proportional to the high severity of gastritis [15]. In this study, the severity of gastritis was found in the infected groups.

During the normal protein cycle, ADMA is formed enzymatically from the methylation of arginine remnants through the activity of redox-sensitive

Table-2: The mean of ADMA levels in each group.

\begin{tabular}{lccc}
\hline $\begin{array}{l}\text { Experimental } \\
\text { Groups }\end{array}$ & $\mathbf{n}$ & ADMA (nmol/mL) & p-value \\
\hline Group-1 & 6 & $1.04 \pm 0.02$ & $<0.001^{*}$ \\
Group-2 & 6 & $1.41 \pm 0.09$ & \\
Group-3 & 6 & $1.57 \pm 0.21$ & \\
Group-4 & 6 & $1.19 \pm 0.11$ & \\
Group-5 & 6 & $1.12 \pm 0.04$ & \\
\hline
\end{tabular}

The results were mean \pm SD. Statistical test using one-way ANOVA. $* p<0.05$. ADMA $=$ Asymmetric dimethylarginine, $\mathrm{SD}=$ Standard deviation, $\mathrm{ANOVA}=$ Analysis of variance
S-adenosylmethionine-dependent protein arginine $\mathrm{N}$-methyltransferases and metabolized to citrulline by dimethylarginine dimethylaminohydrolase (DDAH) [22]. ADMA levels reported enhancing during induction of gastric injury with ethanol, indomethacin, cold-stress, and H. pylori $[23,24]$. Those finding is concordant with our study. The production of ADMA in H. pylori infection is enhanced by inhibition of antioxidant enzymes activity which leads to the aggregation of reactive oxygen species (ROS) to be cellular oxidative stress and liberation of pro-inflammatory cytokines, such as tumor necrosis factor-alpha (TNF- $\alpha$ ), interleukin-6 (IL-6), and interferon-gamma [25]. Pro-inflammatory cytokines activate protein arginine $\mathrm{N}$-methyltransferases, an ADMA forming enzyme, and alleviates DDAH activity that degrades ADMA [23]. H. pylori infection leads to a life-long inflammation by inducing various gastric mucosal mediators in regulating the mobility of neutrophils, macrophages, and other leukocytes, which associated with gastric mucosal disintegration [26]. The enhancement of ADMA levels is closely related to the gastric mucosal disintegration [27]. Several studies noted that the eradication of $H$. pylori decreases serum ADMA levels [24,28].

We observed that a single administration of C. striata extract (Group-3) induced the highest severity of gastritis and led the increment of ADMA levels, as seen in Group-3. These results might be associated with the destruction of $C$. striata due to gastric motility disorder, acid, enzymatically, and biofilm formation. C. striata was broken down into albumin, amino acids, fatty acids, and minerals $[29,30]$. Some albumin clusters, such as thiol and sulfhydryl as an antimicrobial and free radical scavenger, respectively, damaged [31]. Damaged thiol clusters cannot penetrate and diffuse to the biofilm matrix so that the antimicrobial property becomes lost [32]. H. pylori requires complex growth media, rich in nutrients, to grow, and form colonies. Once $H$. pylori colonize gastric mucosal hosts, it will utilize host protein and fat metabolism as an energy source. H. pylori energy is obtained from amino acids and fatty acids. Amino acids are needed

Table-3: Post hoc analysis in comparing ADMA levels in each group.

\begin{tabular}{lcccc}
\hline Groups & Mean difference & \multicolumn{2}{c}{} & \multicolumn{1}{c}{ 95\% CI } \\
\cline { 3 - 4 } & & Minimum & Maximum \\
\hline Group-1 versus Group-2 & -0.38 & -0.55 & -0.21 & $0.001^{*}$ \\
Group-1 versus Group-3 & -0.53 & -0.93 & -0.13 & $0.015^{*}$ \\
Group-1 versus Group-4 & -0.15 & -0.36 & 0.06 & 0.179 \\
Group-1 versus Group-5 & -0.08 & -0.15 & -0.01 & $0.027^{*}$ \\
Group-2 versus Group-3 & -0.16 & -0.53 & 0.22 & 0.783 \\
Group-2 versus Group-4 & 0.23 & 0.02 & 0.43 & $0.031^{*}$ \\
Group-2 versus Group-5 & 0.30 & 0.13 & 0.46 & $0.002^{*}$ \\
Group-3 versus Group-4 & 0.38 & 0.01 & 0.76 & $0.047^{*}$ \\
Group-3 versus Group-5 & 0.45 & 0.06 & 0.85 & $0.028 *$ \\
Group-4 versus Group-5 & 0.07 & -0.13 & 0.27 & 0.864 \\
\hline
\end{tabular}

Post hoc Tamhane. The number of rats in each group was 6. $* \mathrm{p}<0.05$. ADMA=Asymmetric dimethylarginine, $\mathrm{CI}=$ Confidence interval 
to increase the motility and chemotaxis properties. Motility regulated by chemotaxis is essential in the H. pylori growth cycle and colonization [33]. H. pylori use aspartate and glutamate to facilitate the production of ammonia by the activity of urease enzyme to reduce gastric acidity level to survive and increase the adhesion to gastric epithelial cells, particularly in the early stage of colonization. Besides, arginine, aspartate, glutamate, and serine also play a role as a source of carbon energy for $H$. pylori in protein synthesis, virulence, and resistance to stress [34]. Biosynthesis of unsaturated fatty acids is needed by $H$. pylori to maintain function and membrane structure. At the same time, minerals are necessary to modify $H$. pylori gene expression so that virulence factors become more effective in forming colonization $[35,36]$. C. striata extract contains major nutrients, such as albumin, amino acids (arginine, lysine, aspartic acid, and glutamic acid), fatty acids, and minerals. Briefly, in vivo, a single administration of $C$. striata extract in gastritis $H$. pylori enhances growth and $H$. pylori density because the nutrients of $C$. striata extract might become a source of food or energy for $H$. pylori growth as we observed in Group-3.

The single standard eradication regimen administration in Group-4 showed a decrease in the severity of gastritis and the reduction of ADMA levels compared to Group-3. The standard eradication regimen comprises omeprazole, amoxicillin, and clarithromycin. The existence of omeprazole lowers gastric acidity and makes the antimicrobial performance more optimal [37]. The reduction of gastric acidity level increases gastric amoxicillin concentration and exceeds the minimum inhibitory concentration to H. pylori $[7,38]$. Clarithromycin acts by binding to the $50 \mathrm{~s}$ bacterial ribosome subunit to inhibit the synthesis of $H$. pylori protein. A combination of two antimicrobials, amoxicillin and clarithromycin, induce the increase of the eradication rate [7].

Administration, a combination of standard eradication regimen and $C$. striata extract, showed favorable results; this was seen in Group-5, where there was an improvement in the severity of gastritis and decreased ADMA levels. A significant difference was shown in the severity of gastritis, when we compared Group-5 to Group-4 (single administration of standard eradication regimen group). As we noticed in Group4, soon after omeprazole administration, there was a decrease in gastric acidity, followed by an increase in the performance of both antimicrobials so that there was a decrease of ADMA levels and the improvement of the severity of gastritis. The addition of $C$. striata apparently reduces more ADMA levels, the number of bacteria, and further improves the severity of gastritis, as showed in gastric histological examination. This finding in Group-5 indicates the potentiation effect between standard eradication regimen in eradicating $H$. pylori and $C$. striata extract as an anti-inflammatory, respectively.
Anti-inflammatory properties of $C$. striata extract due to the presence of major nutrients contents such as albumin, amino acids (arginine, lysine, aspartic acid, and glutamic acid), fatty acids, and minerals. Albumin and minerals (zincum, cuprum, and ferrum) possess an antioxidant property that acts as ROS scavenger and cellular protection against oxidative stress [10]. Some amino acids, such as arginine, a substrate in forming NOS, arginase enzymes, and originator of the immune response [39], where lysine, aspartic acid, glutamic acid, and other amino acids perform as antioxidant synergistically with some fatty acids [10]. There are many potent anti-inflammatory properties of these fatty acids. Linoleic acid blocks inflammation by depressing the production of leukotriene B4, a substance that induces the production of TNF- $\alpha$ [40]. Linoleic and arachidonic acids impede the production of pro-inflammatory cytokines such as IL-1 $\beta$, IL-6, and TNF- $\alpha$ [41]. Oleic and stearic acids act by debilitating the expression of endothelial leukocytes adhesion molecules and reducing the polymorphonuclear leukocytes (PMNs) activity, respectively. The reduction of PMNs activity can prevent ROS release, which can cause tissue damage [42].

\section{Conclusion}

We concluded that a single administration of C. striata extract worsens the severity of gastritis and increases serum ADMA levels in the $H$. pylori gastritis rat model. The administration of a combination of standard eradication regimen and $C$. striata extract reduces serum ADMA levels and significantly improves the severity of gastritis compared to the administration of a single $C$. striata extract and a single standard eradication regimen.

\section{Authors' Contributions}

OKY, AL, SI, and RLK designed and supervised the study. OKY did laboratory works, interpreted the data, drafted, and wrote the manuscript. AL was involved in preparing and critical checking of the manuscript. SI analyzed data and critical checking of the manuscript. RLK participated in the collection of data, laboratory works, and preparation of the manuscript. All authors read and approved the final manuscript.

\section{Acknowledgments}

The authors thank the head and staff of Biomedical Research Unit, West Nusa Tenggara Province General Hospital, for providing facilities for this research. The authors did not receive any funds for this study.

\section{Competing Interests}

The authors declare that they have no competing interests.

\section{Publisher's Note}

Veterinary World remains neutral with regard to jurisdictional claims in published institutional affiliation. 


\section{References}

1. Camilo, V., Sugiyama, T. and Touati, E. (2017) Pathogenesis of Helicobacter pylori infection. Helicobacter, 22(S1): 1-6.

2. Wang, F., Meng, W., Wang, B. and Qiao, L. (2014) Helicobacter pylori-induced gastric inflammation and gastric cancer. Cancer Lett., 345(2): 196-202.

3. Magierowski, M., Jasnos, K., Sliwowski, Z., Surmiak, M., Krzysiek-Maczka, G., Ptak-Belowska, A., Kwiecien, S. and Brzozowski, T. (2014) Exogenous asymmetric dimethylarginine (ADMA) in pathogenesis of ischemia-reperfusion-induced gastric lesions: Interaction with protective nitric oxide $(\mathrm{NO})$ and calcitonin gene-related peptide (CGRP). Int. J. Mol. Sci., 15(3): 4946-4964.

4. Szlachcic, A., Maczka, G.K., Pajdo, R., Targosz, A., Magierowski, M., Jasnos, K., Drozdowicz, D., Kwiecien, S. and Brzozowski, T. (2013) The impact of asymmetric dimethylarginine (ADAMA), the endogenous nitric oxide (NO) synthase inhibitor, to the pathogenesis of gastric mucosal damage. Curr. Pharm. Des., 19(1): 90-97.

5. Notsu, Y., Yano, S., Shibata, H., Nagai, A. and Nabika, T. (2015) Plasma arginine/ADMA ratio as a sensitive risk marker for atherosclerosis: Shimane CoHRE study. Atherosclerosis, 239(1): 61-66.

6. Avci, B., Alacam, H., Dilek, A. and Kozan, A. (2015) Effects of asymmetric dimethylarginine on inflammatory cytokines (TNF- $\alpha$, IL-6 and IL-10) in rats. Toxicol. Ind. Health, 31(3): 268-273.

7. Debraekeleer, A. and Remaut, H. (2018) Future perspective for potential Helicobacter pylori eradication therapies. Future Microbiol., 13(6): 671-687.

8. Khien, V.V., Thang, D.M., Hai, T.M., Duat, N.Q., Khanh, P.H., Ha, D.T., Binh, T.T., Dung, H.D.Q., Trang, T.T.H. and Yamaoka, Y. (2019) Management of antibiotic-resistant Helicobacter pylori infection: Perspectives from Vietnam. Gut Liver, 13(5): 483-497.

9. Khan, M.S.A., Jais, A.M.M., Hussain, J., Siddiqua, F., Reddy, A.G., Shivakumar, P. and Madhuri, D. (2014) Gastroprotective effect of freeze dried stripped snakehead fish (Channa striata Bloch.) aqueous extract against aspirin induced ulcerogenesis in pylorus ligated rats. ISRN Pharmacol, 2014(327606): 1-8.

10. Rahman, M., Molla, M., Sarker, M., Chowdhury, S. and Shaikh, M. (2018) Snakehead fish (Channa striata) and its biochemical properties for therapeutics and health benefits. SF J. Biotechnol. Biomed. Eng., 1(1): 1-5.

11. Hidayati, D., Faizah, A., Prasetyo, E.N., Jadid, N. and Abdulgani, N. (2018) Antioxidant capacity of Snakehead fish extract (Channa striata) at different shelf life and temperatures. J. Phys. Conf. Ser., 1028(1): 1-5.

12. Zulaikha, N., Zawawi, M., Shaari, R., Nordin, M.L., Hamdan, R.H., Peng, T.L., Salma, C.W. and Zalati, C.W. (2020) Antibacterial and cytotoxic activity assessment of Channa striatus (Haruan) extract. Vet. World., 13(3): 508-514.

13. Andini, A. and Prayekti, E. (2019) Chitosan as antifungal in Channa striata collagen chitosan for wound healing. Med. Health Sci. J., 3(2): 8-11.

14. Muhtadi, M., Annissa Y.N., Suhendi, A. and Sutrisna, E. (2018) Hypoglycemic effect of Zingiber zerumbet ethanolic extracts and Channa striata powder in alloxan-induced diabetic rats. J. Nutraceuticals Herb. Med., 1(1): 9-15.

15. Hassan, T.M., Al-Najjar, S., Al-Zahrani, I., Alanazi, F.B. and Alotibi, M. (2016) Helicobacter pylori chronic gastritis updated Sydney grading in relation to endoscopic findings and $H$. pylori IgG antibody: Diagnostic methods. J. Microsc. Ultrastruct., 4(4): 167-174.

16. Werawatganon, D. (2014) Simple animal model of Helicobacter pylori infection. World J. Gastroenterol., 20(21): 6420-6424.

17. Eren, M., Colak, O., Işiksoy, S. and Yavuz, A. (2015) Effect of $H$. pylori infection on gastrin, ghrelin, motilin, and gastroesophageal reflux. Turk. J. Gastroenterol., 26(5): 367-372.

18. Zhang, C.L., Geng, C.H., Yang, Z.W., Li, Y.L., Tong, L.Q., Gao, P. and Gao, Y.Q. (2016) Changes in patients' symptoms and gastric emptying after Helicobacter pylori treatment. World J. Gastroenterol., 22(18): 4585-4593.

19. Lu, L.J., Hao, N.B., Liu, J.J., Li, X. and Wang, R.L. (2018) Correlation between Helicobacter pylori infection and metabolic abnormality in general population: A cross-sectional study. Gastroenterol. Res. Pract., 2018: 1-6.

20. Hathroubi, S., Servetas, S.L., Windham, I., Merrell, D.S. and Ottemann, K.M. (2018) Helicobacter pylori biofilm formation and its potential role in pathogenesis. Microbiol. Mol. Biol. Rev, 82(2): 1-15.

21. Yonezawa, H., Osaki, T. and Kamiya, S. (2015) Biofilm formation by Helicobacter pylori and its involvement for antibiotic resistance. Biomed. Res. Int., 2015(914791): 1-9.

22. Chandra, D., Poole, J.A., Bailey, K.L., Staab, E., Sweeter, J.M., DeVasure., J.M., Romberger, D.J. and Wyatt, T.A. (2018) Dimethylarginine dimethylaminohydrolase (DDAH) overexpression enhances wound repair in airway epithelial cells exposed to agricultural organic dust. Inhal. Toxicol., 30(3): 133-139.

23. Tain, Y.L. and Hsu, C.N. (2017) Toxic dimethylarginines: Asymmetric dimethylarginine (ADMA) and symmetric dimethylarginine (SDMA). Toxins, 9(3): 66-72.

24. Baldane, S., Korkmaz, H., İpekçi, S.H., Sözen, M., Abuşoğlu, S., Akar, T., Ünlü, A. and Kebapcılar, L. (2017) Changes in serum levels of ADMA, SDMA and L-NMMA with Helicobacter pylori eradication. J. Acad. Res. Med., 7 : 132-134.

25. Kountouras, J., Boziki, M., Polyzos, S.A., Katsinelos, P., Gavalas, E., Zeglinas, C., Tzivras, D., Romiopoulos, I., Giorgakis, N., Anastasiadou, K., Vardaka, E., Kountouras, C., Kazakos, E., Xiromerisiou, G., Dardiotis, E. and Deretzi, G. (2017) Impact of reactive oxygen species generation on Helicobacter pylori-related extragastric diseases: A hypothesis. Free Radic. Res., 51(1): 1-7.

26. White, J.R., Winter, J.A. and Robinson, K. (2015) Differential inflammatory response to Helicobacter pylori infection: Etiology and clinical outcomes. J. Inflamm. Res., 8: 137-147.

27. Zhang, Z., Zou, Y.Y., Li, F.J. and Hu, C.P. (2011) Asymmetric dimethylarginine: A novel biomarker of gastric mucosal injury? World J. Gastroenterol., 17(17): 2178-2180.

28. Aydemir, S., Eren, H., Tekin, I.O., Harmandar, F.A., Demircan, N. and Cabuk, M. (2010) Helicobacter pylori eradication lowers serum asymmetric dimethylarginine levels. Mediators Inflamm., 2010(685903): 18-22.

29. Purnamawati, Djokosetiyanto, D., Nirmala, K., Harris, E. and Affandi, R. (2017) Survival and growth responses of snakehead fish Channa striata Bloch. Juvenile in aerated and unaerated acid sulfate water. J. Akuakult. Indones., 16(1): 60-67.

30. Sakti, H., Lestari, S. and Supriadi, A. (2016) Quality changes of smoked Snakehead fish (Channa striata) during storage. J. Teknol. Has. Perikan., 5(1): 11-18.

31. Kragh-Hansen, U. (2018) Possible mechanisms by which enzymatic degradation of human serum albumin can lead to bioactive peptides and biomarkers. Front. Mol. Biosci., 5(63): 1-6.

32. Arzumanyan, V., Ozhovan, I. and Svitich, O. (2019) Antimicrobial effect of albumin on bacteria and yeast cells. Bull. Exp. Biol. Med., 167(6): 763-766.

33. Abdollahi, H. and Tadjrobehkar, O. (2012) The role of different sugars, amino acids and few other substances in chemotaxis directed motility of Helicobacter pylori. Iran. J. Basic Med. Sci., 15(3): 787-794.

34. Leduc, D., Gallaud, J., Stingl, K. and de Reuse, H. (2010) Coupled amino acid deamidase-transport systems essential for Helicobacter pylori colonization. Infect. Immun., 78(6): 2782-2792. 
35. Bi, H., Zhu, L., Jia, J., Zeng, L. and Cronan, J.E. (2016) Unsaturated fatty acid synthesis in the gastric pathogen Helicobacter pylori proceeds via a backtracking mechanism. Cell. Chem. Biol., 23(12): 1480-1489.

36. Haley, K.P. and Gaddy, J.A. (2015) Metalloregulation of Helicobacter pylori physiology and pathogenesis. Front. Microbiol., 6(911): 1-14.

37. Mori, H. and Suzuki, H. (2019) Role of acid suppression in acid-related diseases: Proton pump inhibitor and potassium-competitive acid blocker. J. Neurogastroenterol. Motil., 25(1): 6-14.

38. Brito, B.B., Silva, F.A.F., Soares, A.S., Pereira, V.A., Santos, M.L.C., Sampaio, M.M., Neves, P.H.M. and de Melo, F.F. (2019) Pathogenesis and clinical management of Helicobacter pylori gastric infection. World $J$. Gastroenterol., 25(37): 5578-5589.

39. Wijnands, K.A.P., Castermans, T.M.R., Hommen, M.P.J.,
Meesters, D.M. and Poeze, M. (2015) Arginine and citrulline and the immune response in sepsis. Nutrients, 7(3): 1426-1463.

40. Dahlan-Daud, C.K., Mat Jais, A.M., Ahmad, Z., Akim, A.M. and Adam, A. (2010) Amino and fatty acid compositions in Haruan traditional extract (HTE). Bol. Latinoam. Caribe Plantas Med. Aromat., 9(5): 414-429.

41. Wall, R., Ross, R.P., Fitzgerald, G.F. and Stanton, C. (2010) Fatty acids from fish: The anti-inflammatory potential of long-chain omega-3 fatty acids. Nutr. Rev., 68(5): 280-289.

42. Ambrozova, G., Martiskova, H., Koudelka, A., Ravekes, T., Rudolph, T.K., Klinke, A., Rudolph, V., Freeman, B.A., Woodcock, S.R., Kubala, L. and Pekarova, M. (2016) Nitro-oleic acid modulates classical and regulatory activation of macrophages and their involvement in pro-fibrotic responses. Free Radic. Biol. Med., 90: 252-260.

\section{$* * * * * * * *$}

